\title{
Comparison Between Sensory and Nephelometric Evaluations of Tannin Fractions Obtained by Ultrafiltration of Red Wines
}

\author{
Pierrick Rébénaque • André Rawyler • \\ Marc-Olivier Boldi • Pascale Deneulin
}

Received: 11 June 2014 / Accepted: 16 January 2015 /Published online: 5 February 2015

(C) Springer Science+Business Media New York 2015

\begin{abstract}
Introduction Although the assessment of red wine quality relies primarily on a sensory description of tannins, it may be usefully completed by some knowledge of the physicochemical properties of these tannins. The present study has a double aim: (1) to gain insight into the sensory properties of subpopulations of proanthocyanidic tannins of different molecular sizes (obtained through several ultrafiltration steps), as well as into the kinetics of the haze formed by these fractions when reacted with polyvinylpyrrolidone (as measured by nephelometry) and (2) to determine whether a correlation exists between the sensory and the nephelometric data.

Materials and Methods To this end, two wines from different grape varieties were sequentially ultrafiltered to provide three tannic fractions which differed by the range of their polymerization degrees. Then, these fractions were added (individually or in combination) into their native wine matrix (previously deprived of all its polyphenols via charcoal treatment) according to a specific experimental design. These reconstituted wines were characterized by nephelometry and by a static (quantitative descriptive analysis) and a dynamic (temporal dominance of sensations) sensory method.
\end{abstract}

P. Rébénaque $(\bowtie) \cdot A$. Rawyler $\cdot$ P. Deneulin

University of Applied Sciences and Arts, Western Switzerland -

CHANGINS, Viticulture and Oenology, Route de Duillier 50, Case postale 1148, 1260 Nyon, Switzerland

e-mail: pierrick.rebenaque@changins.ch

A. Rawyler

e-mail: andre.rawyler@changins.ch

P. Deneulin

e-mail: pascale.deneulin@changins.ch

M.-O. Boldi

Research Center for Statistics, University of Geneva- GSEM,

Boulevard du Pont-d'Arve 40, 1211 Genève 4, Switzerland

e-mail: marc-olivier.boldi@unige.ch
Results and Discussion Wines containing the largest size tannins (highest range of polymerization degrees) were perceived as more astringent and cause drying in the mouth and after spitting. Concerning the temporality of perception, wines containing the fraction with the largest tannins provide long inmouth drying, and the astringency and in-mouth drying perceptions were the most persistent features.

Conclusion Finally, a highly positive correlation between nephelometric and quantitative descriptive analysis data was shown.

Keywords Sensory evaluation - Temporal Dominance of Sensations · Astringency $\cdot$ Nephelometry $\cdot$ Tannin · Ultrafiltration

\section{Introduction}

The perception of red wine quality is particularly linked with the perception of its astringency and the intensity of astringency perceived in a product reflects its level of acceptability. For example, Törnwall et al. (2011) have shown that apple juice with added tannic acid was perceived as less pleasant and more intense than the pure apple juice. Astringency is mostly due to interactions between salivary proteins and wine polyphenols, forming aggregates which precipitate. These aggregates are characterized by a drying and rough inmouth impression (Gawel et al. 2001; Bate-Smith 1954). Astringency is considered as a tactile rather than a taste sensation (Green 1993; Lea 1992). The concentration of the proanthocyanidic tannin compounds in a wine determines their mouth-feel properties (Vidal et al. 2004). They are extracted during alcoholic fermentation and post-fermentation maceration (Ribéreau-Gayon et al. 1998). Wine sensory perceptions are influenced by vine treatment and vintage (Holt et al. 2008). Vidal et al. (2004) showed that proanthocyanidic 
tannins are involved in the astringent sensation, defined as a loss of lubricant properties of the saliva through protein and glycoprotein precipitations.

Human saliva represents an important element for the perception of astringency and bitterness. It is an aqueous fluid, composed of $99 \%$ water which contains proteins, sugars, and hormones together with other components (Wu et al. 1994). Salivary proteins are mainly mucins and proline-rich proteins (PRPs). Astringency is primarily due to interactions between tannins, mucins, and PRPs (Green 1993). These proteins exhibit a high affinity for tannins due to their multiple proline-rich sequences (Hagerman and Butler 1981). The influence of the saliva on mouth-feel sensations is specifically determined by the saliva flow and its composition (Dinnella et al. 2011; Condelli et al. 2006; Kauffman and Keller 1979). Quintana et al. (2009) have shown that saliva patterns were modified after some bitter stimulus. The amount and the nature of the proteins also take part in the perception of astringency. Whenever present in small quantities, proteins bind to the available tannins to form soluble complexes, though less hydrophilic. An increase of the protein concentration leads to a binding phenomenon between proteins due to the polyphenols (McManus et al. 1981). Protein precipitation increases and so does also the astringent perception.

Nephelometry was adapted for the study of particular environments in which quick formation and disappearance of scattering particles occurred (Carvalho et al. 2006; Freitas and Mateus 2002; Chapon 1993). Mateus et al. (2004) analyzed the interactions between salivary proteins and tannins by measuring the light scattered by colloidal solutions and suspensions. The influence of several factors such as the type of protein and reactant concentrations was determined to get an insight into the in-mouth tannin-salivary protein interactions. The first reaction occurs between a protein and a tannin molecule and is followed by the association of several of these 1:1 complexes. When sufficiently sized, these associations, called "bricks", become able to scatter visible light. Further aggregation of bricks leads to the formation of larger particles (Saucier et al. 1997). Once the highest haze value is reached, further addition of a binder like polyvinylpyrrolidone (PVP) results in a redistribution of the tannin molecules over PVP chains, and the haze progressively vanishes. In the present study, we used a tannin-polyvinylpyrrolidone reaction, which is based on the formation of hydrogen bridges between hydroxyl and carbonyl groups, thus mimicking the in-mouth tannin-protein association (Guinard et al. 1986). The kinetics and dependence of haze formation and disappearance as a function of the PVP amount added to the wine sample offers useful information on the affinity between the tannin subpopulations and PVP. Measuring the evolution of the turbidity level proved to be a quick and sensitive method to monitor the reversible formation of the tannin-protein complexes and to characterize the types of tannins (Monteleone et al. 2004; Chapon 1993).
The objectives of the present study are: (1) gaining insight into the sensory properties (studied by Quantitative Descriptive Analysis and Temporal Dominance of Sensations) of subpopulations of proanthocyanidic tannins of different molecular sizes (obtained via ultrafiltration), as well as into the kinetics of the haze (studied by nephelometry) formed by these fractions when brought into contact with PVP and (2) to determine whether a correlation exists between sensory and nephelometric data. Ultrafiltration preserves most physicochemical properties of the wine matrix such as $\mathrm{pH}$, total acidity, volatile acidity, alcohol content, and small polyphenols (e.g., anthocyanins, flavanols, etc.). The tannin structural parameter considered here is the molecular size (or mass) which was operationally determined by the molecular mass cutoff value of the ultrafiltration membranes, which can be considered equivalent to the degree of polymerization (DP). Each tannic fraction bracketed between two membranes differing in their cutoff value is therefore characterized by a DP range. It is worth emphasizing that DP range described here should not be confused with the more commonly used mean DP (mDP). This study was organized in three different steps, as follows: (1) to prepare several wine fractions differing only by the DP range of their tannin subpopulations, (2) to characterize these different tannin fractions by the nephelometric method, and (3) to investigate the sensory impact of these fractions using quantitative descriptive analysis (QDA) and temporal dominance of sensations (TDS). Finally, the relationship between the data provided by these three approaches was studied.

\section{Materials and Methods}

\section{Wine Samples}

Initially, we attempted to increase the concentration of a particular wine fraction by $25 \%$ in the original wine, but the panelists failed to observe any sensory difference between samples before and after enrichment at this concentration. There are several reasons for that. Given the native tannin concentration of the original wines, a $25 \%$ concentration increment in a particular tannin subpopulation might have brought the wine close to saturation level. Alternatively, the discriminability between both wines has been masked by the high tannin background of the original wines ( 2.4 to $2.7 \mathrm{~g} / \mathrm{l}$ ), as determined by acidic butanolysis (Porter et al. 1985). Therefore, we decided to remove the original wine tannin background by diluting the wine fractions in a polyphenoldeprived wine matrix, expecting that the organoleptic characteristics of our wine fractions could be enhanced.

Two Swiss wines differing in tannin content (Gamay and Merlot, from the Schenk Winery SA, Rolle, Switzerland) were selected. Both wines (100 l each) were stored at $15^{\circ} \mathrm{C}$ in stainless steel tanks until used. Part of each wine was 
ultrafiltered into four fractions of different DP range. The other part, deprived of all its polyphenols by charcoal treatment (charcoal from Granucol FA, Erbslöh, Geisenheim, Germany), served as a "close-to-natural matrix" instead of using a standard model wine. New "wine" samples were then reconstituted by mixing appropriate volumes of the various fractions and of the wine matrix.

\section{Ultrafiltration of Wines}

Original wines were submitted to four successive ultrafiltration steps on regenerated cellulose membranes of decreasing porosity. An Amicon 8400 stirred ultrafiltration cell of $400 \mathrm{ml}$ (Millipore, Billerica, USA) coupled to a reservoir of $800 \mathrm{ml}$ capacity was used under a maximal nitrogen pressure of 5 bars. All operating guidelines of the fabricant were strictly followed. Four tannic fractions were obtained, noted B for big (tannins of DP range $>30$ ), M1 for medium 1 (tannins of DP range between 15 and 30), M2 for medium 2 (tannins of DP range between 10 and 15), and $\mathrm{S}$ for small (tannins of DP range between 4 and 10). They were operationally defined by their different DP ranges, which were determined by the cutoff thresholds of two successive membrane filters. The theoretical DP range was then calculated by dividing the molecular mass range bracketed by two successive membranes by the average value of 300 dalton $(\mathrm{Da})$ for each monomeric tannin unit. At the end of the ultrafiltration process, each fraction was concentrated 20-25 times.

\section{Polyphenol Deprivation of Wines and Enological Analyses}

The two original wines were treated with charcoal at $26.7 \mathrm{~g} / 1$. The wine bottles were capped and horizontally incubated overnight at ambient temperature on a reciprocal shaker to keep the charcoal in suspension, and the wines were filtered the next day on filter paper (Schleicher \& Schuell BioScience $\mathrm{GmbH}$, Dassel, Germany). The filtered wines were successfully deprived of all polyphenols (tannins, anthocyans, flavanols, and acidic phenols), as shown by spectral and high-performance liquid chromatography (HPLC) analysis and were therefore used as "wine matrix" (bare wine of Table 1) for the various fractions.

\section{Experimental Design}

Four parameters were included in the model: grape variety and the three fractions B, M1, and S. Due to its low tannin content, fraction M2 was not used. Each fraction was added, alone or in combination, to the corresponding wine matrix, to an extent of $25 \%$ of its amount in the original wine. For instance, to prepare 11 of new sample containing fractions B and M1, a volume of each concentrated fraction corresponding to $250 \mathrm{ml}$ of the original wine was added to a sufficient volume of wine
Table 1 Analytic values: alcohol level, $\mathrm{pH}$, and total acidity corrected as tartaric acid equivalents, degree of polymerization of the original and bare wines

\begin{tabular}{lllll}
\hline Sample & $\begin{array}{l}\text { Alcohol } \\
\text { level } \\
(\% v / v)\end{array}$ & $\mathrm{pH}$ & $\begin{array}{l}\text { Total acidity } \\
\text { corrected as tartaric } \\
\text { acid equivalent }\end{array}$ & $\begin{array}{l}\text { Degree of } \\
\text { polymerization }\end{array}$ \\
\hline Merlot & 12.99 & 3.8 & 4.39 & 14 \\
Merlot bare & 12.42 & 3.66 & 4.5 & 11 \\
Gamay & 13.19 & 3.63 & 4.55 & 15 \\
Gamay bare & 13.05 & 3.53 & 4.72 & 9 \\
\hline
\end{tabular}

matrix to make 11 . In view of the significant number of samples for a complete design (16 samples), we firstly used an incomplete experimental design (type $2^{4-1}$ ) (Table 2). Two supplementary samples were added to obtain a series of 10 samples of different tannic nature (design A) including the two extreme samples for Gamay and Merlot, one with all fractions and another one without any fraction. After having analyzed results from design $\mathrm{A}$, which took 4 months, we decided to complete the first partial design by a second series (design B) to increase the number of data and the quality of results. At the end, we obtained all samples included in the completed design type $2^{4}$ by merging designs $\mathrm{A}$ and $\mathrm{B}$. Two samples (extreme ones) were replicated to ensure the stability of products after these 4 months.

Nephelometric Analysis

Nephelometry experiments were performed as follows: A typical glass cuvette $(2 \times 1 \mathrm{~cm})$ contained $0.8 \mathrm{ml}$ of saturated

Table 2 Experimental design of type $2^{4}$. Samples 1 to 10 are included in design A, samples 9 to 16 in design $\mathrm{B}$

\begin{tabular}{llllll}
\hline Sample & Design & $\begin{array}{l}\text { Tannins }>30 \\
\text { subunits=B }\end{array}$ & $\begin{array}{l}30>\text { Tannins }>15 \\
\text { subunits=M1 }\end{array}$ & $\begin{array}{l}\text { 10>Tannins }>4 \\
\text { subunits }=\text { S }\end{array}$ & $\begin{array}{l}\text { Grape } \\
\text { variety }\end{array}$ \\
\hline 1 & A & No & No & No & Gamay \\
2 & A & Yes & No & No & Merlot \\
3 & A & No & Yes & No & Merlot \\
4 & A & Yes & Yes & No & Gamay \\
5 & A & No & No & Yes & Merlot \\
6 & A & Yes & No & Yes & Gamay \\
7 & A & No & Yes & Yes & Gamay \\
8 & A & Yes & Yes & Yes & Merlot \\
9 & A and B & Yes & Yes & Yes & Gamay \\
10 & A and B & No & No & No & Merlot \\
11 & B & Yes & No & No & Gamay \\
12 & B & No & Yes & No & Gamay \\
13 & B & No & No & Yes & Gamay \\
14 & B & Yes & Yes & No & Merlot \\
15 & B & Yes & No & Yes & Merlot \\
16 & B & No & Yes & Yes & Merlot \\
\hline
\end{tabular}


ammonium sulfate, a sample $(0.1$ or $0.3 \mathrm{ml})$ and degased water (previously adjusted to $\mathrm{pH} 4$ with a trace amount of tartaric acid) up to an initial volume of $4 \mathrm{ml}$. The cuvette was magnetically stirred and thermostated at $25^{\circ} \mathrm{C}$. A solution of soluble PVP (Fluka, Buchs, Switzerland) at $0.04 \%(w / v)$, used as a stable protein substitute to mimic salivary proteins, was injected at a constant rate of $1.8 \mathrm{ml} / \mathrm{h}$ by an infusion pump. Turbidity was measured as the amount of scattered light at $90^{\circ}$ with a Pfeuffer nephelometer (Pfeuffer $\mathrm{GmbH}$, Kitzingen, Germany) and expressed in nephelometric turbidity units (NTU). The nephelometer, controlled by a software (Tannolab 2.03 software, Pfeuffer GmbH, Kitzingen, Germany), was able to measure the haze caused by the progressive PVP injection in European Brewery Convention (EBC) units. Each sample was measured successively with a small $(100 \mu \mathrm{l})$ and a large $(300 \mu \mathrm{l})$ volume.

\section{Sensory Analysis}

\section{Quantitative Descriptive Analysis}

The first sensory analysis consisted of a QDA. Twenty-three and 18 panelists participated respectively to the first (design A) and second (design B) sessions of QDA. All panelists were trained weekly for 18 months on different sensory research projects before taking part to this study. A specific tasting vocabulary was developed for this study with all of them based on the mouth-feel wheel developed by Gawel et al. (2000). Each attribute was defined (Table 3) and the final list included seven attributes: acidity, bitterness, astringency, volume, roughness, in-mouth drying, and drying after spitting.

Three specific training sessions focused on the oral perceptions described above. Several sand papers were used to illustrate the scale of roughness. Standard solutions of aluminum sulfate $(0.5$ to $2 \mathrm{~g} / \mathrm{l})$, tartaric acid $(0.25$ to $1.5 \mathrm{~g} / \mathrm{l})$, quinine sulfate $(0.007$ to $0.020 \mathrm{~g} / \mathrm{l})$, tannic acid $(0.25$ to $0.5 \mathrm{~g} / \mathrm{l})$, and carboxymethylcellulose (CMC) $(0.5$ to $1 \mathrm{~g} / \mathrm{l})$ were used as references in a blended or a pure solution at different concentrations. The first training period contained ten different solutions. The second and third ones included six solutions and four wines. The panel evaluated the perception intensity of the solutions for each attribute on a linear scale starting at 0 (not perceived) at the left end to 10 at the right end (highest intensity).

The final tasting (of designs A and B) was performed in sensory booths under white light. The panel evaluated the intensity of the seven attributes on a $10-\mathrm{cm}$ linear scale from 0 (weak) to 10 (strong) for each sample served. The samples were coded and served at ambient temperature around $22{ }^{\circ} \mathrm{C}$. The presentation of the samples was balanced according to the William Latin-square. Wines were served in black INAO glasses $(40 \mathrm{ml})$ covered with plastic petri dishes. Breaks of $90 \mathrm{~s}$ were taken between each sample. These breaks served to
Table 3 Definition of attributes used for sensory evaluation

\begin{tabular}{|c|c|}
\hline Attribute & Definition \\
\hline Acidity & $\begin{array}{l}\text { Describes the acid taste caused by aqueous dilute solutions } \\
\text { of acid compounds such as citric acid or tartaric acid } \\
\text { (ISO 5492:1992). }\end{array}$ \\
\hline Bitterness & $\begin{array}{l}\text { Describes the bitter taste caused by aqueous dilute solutions } \\
\text { of bitter compounds such as quinine (quinine sulfate) or } \\
\text { cafeine (ISO 5492:1992). }\end{array}$ \\
\hline Astringency & $\begin{array}{l}\text { Describes the complex sensation coming from contraction of } \\
\text { mucosae, done by substance such as tannin (aluminum } \\
\text { sulfate) or sloe berry (ISO 5492:1992). }\end{array}$ \\
\hline Volume & $\begin{array}{l}\text { Feeling of the occupation of mouth cavity by a standard } \\
\text { volume of wine ( } 10 \mathrm{ml}) \text { (Granès, Pic-Blateyron, Negrel, } \\
\text { and Bonnefond 2009). Carboxymethylcellulose is used in } \\
\text { this study. }\end{array}$ \\
\hline Roughness & $\begin{array}{l}\text { Evaluation of the size of molecular complexes arising from } \\
\text { interaction between salivary protein and wine tannin. } \\
\text { Roughness is evaluated by scrubbing the tongue with the } \\
\text { palate and compared with the sensations of different } \\
\text { sandpaper (tannic acid). }\end{array}$ \\
\hline $\begin{array}{r}\text { In-mouth } \\
\text { drying }\end{array}$ & $\begin{array}{l}\text { Sensation of lack of lubrication, lack of saliva between gums } \\
\text { and cheek. Impression that gums are pasted with cheek } \\
\text { but can be taken apart with light pressure. }\end{array}$ \\
\hline $\begin{array}{l}\text { Drying after } \\
\text { spitting }\end{array}$ & Drying perception evaluated $5 \mathrm{~s}$ after spitting out the wine. \\
\hline
\end{tabular}

Compounds used as references in our study are highlighted in italics

rinse the palate and to eliminate in-mouth sensations with mineral water and bread as advice by Colonna et al. (2004). The version 2.46B of the FIZZ software (Biosystemes, Couternon, France) was used to collect the sensory data. QDA was performed in duplicate.

\section{Temporal Dominance of Sensations}

The second sensory evaluation was TDS which was performed only on the ten samples of design A. For this test, 26 panelists evaluated the ten samples using two replications. This sensory method consists in selecting for each specific time the attribute which is dominant until the sensation ends (Pineau et al. 2009; Labbe et al. 2009). Previously, two other training sessions focused on TDS. The panel assessed the TDS for different solutions with the seven attributes from the above list. The first training session included a red wine enriched with either $4 \mathrm{~g} / \mathrm{l}$ fructose, or $0.002 \mathrm{~g} / \mathrm{l}$ quinine sulfate, or $1 \mathrm{~g} / 1$ tartaric acid, or $0.5 \mathrm{~g} / 1$ tara tannins. Then seven red Swiss wines were evaluated, followed by a discussion. The second training session included the ten samples of this study. Wines $(15 \mathrm{ml})$ were presented in black INAO glasses.

The same attributes were used as for the QDA, except for the attribute roughness which was removed from the TDS sessions, because no temporal roughness information was expected. On the other hand, the attribute saliva returns was introduced to account for the drying time after spitting. Panelists had to select this attribute when they perceived their 
mouth was lubricated again, by clicking on a corresponding button. However, a 2-min break was introduced between samples for rinsing and cleaning the palate with mineral water and bread. An adapted tasting protocol (Meillon et al. 2009) was applied in order to provide homogeneous tasting conditions. The protocol used three successive well-defined time periods: (a) panelists had to take the entire sample $(15 \mathrm{ml})$ into the mouth and start scoring at $0 \mathrm{~s}$, (b) air had to be drawn through the sample at $12 \mathrm{~s}$, and (c) the sample had to be moved around with the tongue before being spat out at $20 \mathrm{~s}$. The first click on the button attribute drying after spitting was done immediately after spitting. As soon as the drying perception vanished, the attribute saliva returns was clicked. Finally, the stop button was clicked when no more sensations were felt.

\section{Data Analysis}

\section{Quantitative Descriptive Analysis}

An analysis of variance (ANOVA) with the main factors, sample and panelist, for each sensory attribute was carried out using the FactoMineR and SensoMineR packages of the Rsoftware (R Development Core Team 2007). The objective of the test was to verify the existence of significant differences between the various samples within each series. Session effects were analyzed using a mixed ANOVA model with five main factors (session, wine variety, and three tannin fractions). For each attribute, the means of the samples of the second session were corrected by subtracting session effects, estimated by using the regression underlying the ANOVA. For the two replicate samples, the means of the evaluations of the two sessions were taken. A nested ANOVA (model 1) was carried out with the means of the 16 samples to analyze the effects of tannin fractions; these effects were then included in the grape variety effects.

$Y_{\mathrm{ij}}=\mu+\alpha_{\mathrm{i}}+\left.\beta_{\mathrm{j}}\right|_{\mathrm{i}}+\varepsilon_{\mathrm{ij}}$

where $\alpha_{\mathrm{i}}$ is grape variety effect, $\left.\beta_{\mathrm{j}}\right|_{\mathrm{i}}$ is fraction effect included into grape variety, and $\varepsilon_{\mathrm{ij}}$ is the model error.

The descriptive data were analyzed by principal component analysis (PCA) on correlation matrix. This helped determining the axes which best explained the scattering of samples. The correlation circle is used to highlight the relationships between attributes. Individual representations of the samples were analyzed in order to visualize the positioning of the samples.

\section{Analysis of Nephelometric Curves}

Each wine fraction gave a specific response depicting turbidity versus PVP dose nephelometric curve. All curves present very similar shape and differ only by their scale. After curve smoothing as performed by the mgcv package of the $\mathrm{R}$

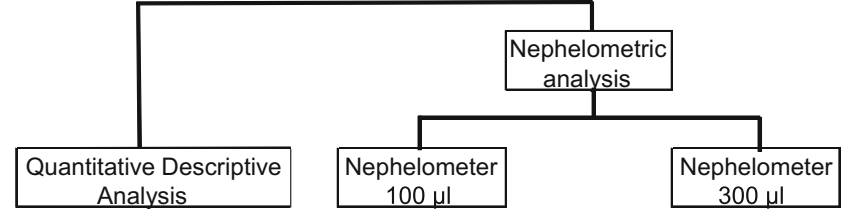

Fig. 1 Sensory and nephelometric data diagram. A multiple factor analysis (MFA) was first carried out on the nephelometric measurements made at low $(100 \mu \mathrm{l})$ and large $(300 \mu \mathrm{l})$ wine volume. A second MFA was then done with the sensory and the global nephelometric data

software proposed by Wood (2006) and normalization, we selected four parameters in order to characterize the 16 samples. These parameters are the $\mathrm{x}$-value at the beginning of the hump (StartX), the X-value at the highest point (HighestX), the highest y-value (HighestY), and the slope on the left-hand side of the hump (Slope). A smoothed line within the graph was used to determine the value of these parameters. HighestX and HighestY were the coordinates of the curve maximum. StartX was found by determining the $\mathrm{x}$-value of the point with the highest gap before reaching the HighestX point. The gap was calculated by running a moving quadratic regression with a span of 30. When the quadratic coefficient was recorded, the window was moved to the right. StartX was the $\mathrm{X}$-value corresponding to the highest quadratic coefficient. A simple linear regression was run on the curve to the left of StartX, which yielded the parameter Slope as the slope of this regression. The same mixed ANOVA model with four main factors (grape variety and three fractions) than QDA analysis was applied (model 1), except that average are used instead of triplicates.

\section{Relationship Between QDA and Nephelometric Analysis}

A hierarchical multiple factor analysis (HMFA) was done using the FactoMineR package to evaluate the multidimensional similarity between the sensory evaluation and the nephelometric data. The structure of the nephelometric data (Fig. 1) was conserved by HMFA (Le Dien and Pagès 2003). The relationship between the two sets of variables (Nephelometer

Table 4 Sample effects of two-way ANOVA respectively in design A and design $\mathrm{B}$

\begin{tabular}{lccccc}
\hline & \multicolumn{2}{l}{ Design A } & & \multicolumn{2}{l}{ Design B } \\
\cline { 2 - 3 } \cline { 5 - 6 } & $F$ & $p$ value & & $F$ & $p$ value \\
\hline Acidity & 1.96 & 0.05 & & 0.31 & NS \\
Bitterness & 0.64 & $\mathrm{NS}$ & & 0.76 & $\mathrm{NS}$ \\
Astringency & 4.63 & $<0.001$ & & 0.81 & 0.01 \\
Volume & 1.88 & 0.06 & & 0.77 & $\mathrm{NS}$ \\
Roughness & 4.74 & $<0.001$ & 3.36 & 0.003 \\
In-mouth drying & 3.38 & 0.001 & 2.56 & 0.02 \\
Drying after spitting & 3.45 & 0.001 & 2.67 & 0.01 \\
\hline
\end{tabular}


Table 5 Means and results of nested ANOVA with the three fractions and grape variety effects (fraction effects are included in grape variety effect)

\begin{tabular}{|c|c|c|c|c|c|c|c|c|c|c|c|c|c|c|c|c|c|}
\hline & \multicolumn{3}{|c|}{ Variety effect } & \multicolumn{5}{|c|}{ B fraction effect } & \multicolumn{5}{|c|}{ M1 fraction effect } & \multicolumn{4}{|c|}{$\mathrm{S}$ fraction effect } \\
\hline & \multirow[b]{2}{*}{ Sign. } & \multirow[b]{2}{*}{ Gamay } & \multirow[b]{2}{*}{ Merlot } & \multirow[b]{2}{*}{ Sign. } & \multicolumn{2}{|c|}{ Gamay } & \multicolumn{2}{|c|}{ Merlot } & \multirow[b]{2}{*}{ Sign. } & \multicolumn{2}{|c|}{ Gamay } & \multicolumn{2}{|c|}{ Merlot } & \multicolumn{2}{|c|}{ Gamay } & \multicolumn{2}{|c|}{ Merlot } \\
\hline & & & & & B & No B & B & No B & & M1 & No M1 & M1 & No M1 & $\mathrm{S}$ & No $\mathrm{S}$ & $\mathrm{S}$ & No $S$ \\
\hline Acidity & $*$ & $5.30 \mathrm{a}$ & $4.93 b$ & & 5.35 & 5.25 & 5.03 & 4.83 & & 5.41 & 5.18 & 4.97 & 4.89 & 5.27 & 5.33 & 4.96 & 4.9 \\
\hline Bitterness & & 3.86 & 3.67 & & 4.04 & 3.68 & 3.78 & 3.55 & & 3.86 & 3.87 & 3.61 & 3.73 & 3.80 & 3.92 & 3.44 & 3.89 \\
\hline Astringency & & 3.36 & 3.09 & $* * *$ & $3.88 \mathrm{a}$ & $2.83 b$ & $3.42 \mathrm{a}$ & $2.76 \mathrm{~b}$ & & 3.37 & 3.35 & 3.15 & 3.03 & 3.29 & 3.43 & 3.27 & 2.91 \\
\hline Volume & & 3.87 & 3.92 & & 3.73 & 4.01 & 3.93 & 3.92 & & 3.73 & 4.01 & 3.94 & 3.91 & 3.80 & 3.94 & 3.72 & 4.13 \\
\hline Roughness & $*$ & $2.85 \mathrm{a}$ & $2.53 \mathrm{~b}$ & $* * *$ & $3.32 \mathrm{a}$ & $2.38 \mathrm{~b}$ & $3.17 \mathrm{a}$ & $1.89 \mathrm{~b}$ & & 2.96 & 2.75 & 2.71 & 2.34 & 2.78 & 2.92 & 2.58 & 2.47 \\
\hline In-mouth drying & $* *$ & $2.94 \mathrm{a}$ & $2.56 \mathrm{~b}$ & $* * *$ & $3.24 \mathrm{a}$ & $2.64 b$ & $2.88 \mathrm{a}$ & $2.23 b$ & $*$ & $3.02 \mathrm{a}$ & $2.85 b$ & $2.79 \mathrm{a}$ & $2.32 \mathrm{~b}$ & 2.82 & 3.05 & 2.67 & 2.44 \\
\hline Drying after spitting & & 2.67 & 2.45 & $* *$ & $3.08 \mathrm{a}$ & $2.27 \mathrm{~b}$ & $2.80 \mathrm{a}$ & $2.11 b$ & & 2.64 & 2.70 & 2.58 & 2.33 & 2.59 & 2.75 & 2.58 & 2.33 \\
\hline
\end{tabular}

Different letters indicate the existence of statistically significant differences. Latin letters $(a, b)$ are used to compare fraction effect ${ }^{*} p<0.05 ; * *<0.01 ; * * * p<0.002$ (stars indicate significant differences among variety or fraction)

and QDA) was evaluated by the RV coefficient and significance according to Josse et al. (2008).

\section{Temporal Dominance of Sensations}

The TDS data reported by the panel were computed using the version $2.46 \mathrm{~B}$ of the FIZZ treatment software (Biosystemes, Couternon, France). The number of clicks for a specific product, time, and attribute was divided by the number of panelists, in order to obtain a dominance rate, i.e., the proportion of panelist which evaluated that a specific attribute was dominant at this specific time for this specific product as described in Meillon et al. (2009). Since each panelist can only have one single dominant attribute at a time, the sum of the dominance rates over attributes is always equal to one. We observed that the higher the dominant rate of an attribute, the closer the agreement between panelists. The "significance level" of $5 \%$ based on a two sided $t$ test is represented by a horizontal line, which expresses the smallest value that was significantly higher $(p=0.05)$ than the level obtained by chance (Meillon et al. 2009). TDS difference curves between samples (Pineau et al. 2009) were also calculated by subtracting the dominance rates of a given sample from the rates of another sample. The different attribute curves were plotted on the same graph only when they were significantly different from zero. Based on a classic test used to compare binomial proportions, the significance level were also determined then plotted on the same graph.

\section{Results and Discussion}

The $\mathrm{pH}$, total acidity corrected as tartaric acid equivalents and alcohol level values obtained for the wine matrix of each grape variety were close to those of original wines, emphasizing that the charcoal treatment did not alter these values with respect to a

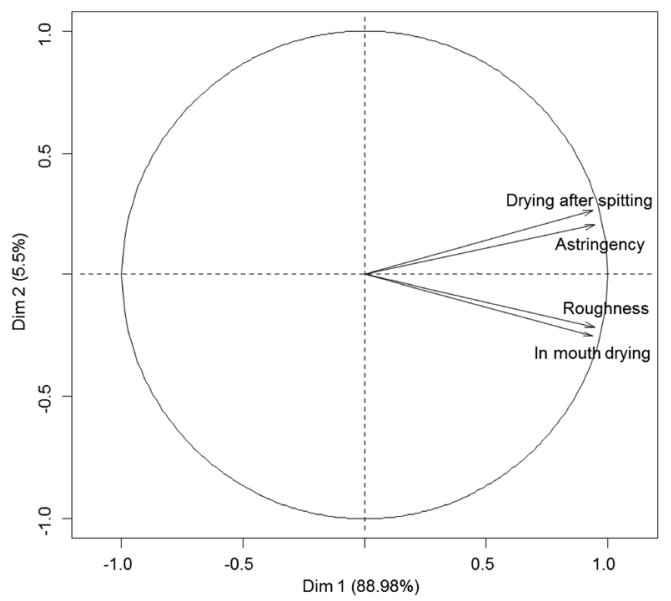

b

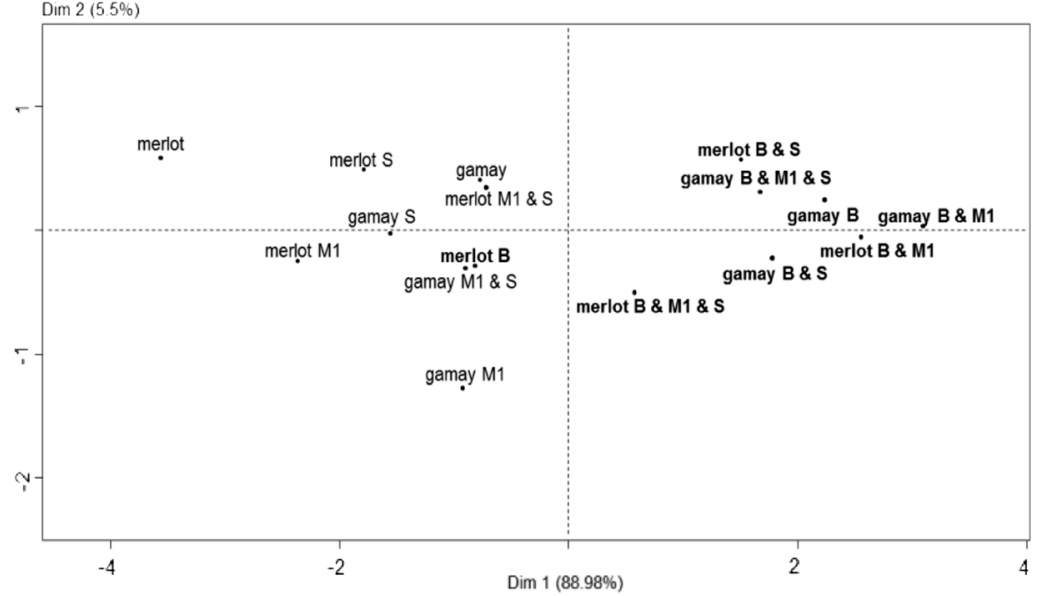

Fig. 2 a, b PCA performed on attributes for which a significant difference has been determined by the ANOVA and which are common to the two sessions and the 16 samples. Correlation of the attributes (a) and scores plot (b). In bold were the samples added from fraction B 
Table 6 Means and results of nested ANOVA with the three fractions and grape variety effects (fraction effects are included in grape variety effect)

\begin{tabular}{|c|c|c|c|c|c|c|c|c|c|c|c|c|c|c|c|c|c|}
\hline & \multicolumn{2}{|c|}{ Variety effect } & \multicolumn{5}{|c|}{ B fraction effect } & \multicolumn{5}{|c|}{ M1 fraction effect } & \multicolumn{5}{|c|}{$\mathrm{S}$ fraction effect } \\
\hline & \multirow[b]{2}{*}{ Gamay } & \multirow[b]{2}{*}{ Merlot } & \multirow[b]{2}{*}{ Sign. } & \multicolumn{2}{|c|}{ Gamay } & \multicolumn{2}{|c|}{ Merlot } & \multirow[b]{2}{*}{ Sign. } & \multicolumn{2}{|c|}{ Gamay } & \multicolumn{2}{|l|}{ Merlot } & \multirow[b]{2}{*}{ Sign. } & \multicolumn{2}{|c|}{ Gamay } & \multicolumn{2}{|l|}{ Merlot } \\
\hline & & & & $\mathrm{B}$ & No B & $\mathrm{B}$ & No B & & M1 & No M1 & M1 & No M1 & & $\mathrm{S}$ & No $S$ & $\mathrm{~S}$ & No $S$ \\
\hline HighestX 100 & 18.36 & 18.83 & $* * *$ & 21.76 & 14.95 & 23.03 & 14.64 & & 19.46 & 17.25 & 18.55 & 19.11 & & 18.54 & 18.18 & 18.23 & 19.44 \\
\hline HighestY 100 & 3.39 & 3.59 & $* * *$ & 4.12 & 2.67 & 4.36 & 2.82 & & 3.78 & 3.01 & 3.91 & 3.27 & $*$ & 3.85 & 2.93 & 3.98 & 3.2 \\
\hline StartX 100 & 7.06 & 7.76 & $* * *$ & 9.58 & 4.55 & 11.30 & 4.23 & & 8.05 & 6.08 & 8.10 & 7.43 & $*$ & 8.23 & 5.90 & 8.03 & 7.5 \\
\hline Slope 100 & 0.13 & 0.12 & & 0.14 & 0.12 & 0.12 & 0.13 & & 0.15 & 0.11 & 0.12 & 0.12 & & 0.15 & 0.11 & 0.14 & 0.11 \\
\hline HighestX 300 & 30.69 & 31.07 & $* * *$ & 38.80 & 22.58 & 40.78 & 21.36 & & 32.20 & 29.18 & 32.85 & 29.29 & & 32.28 & 29.10 & 32.98 & 29.16 \\
\hline HighestY 300 & 7.04 & 7.21 & $* * *$ & 9.59 & 4.48 & 9.76 & 4.66 & & 7.54 & 6.53 & 8.00 & 6.42 & $*$ & 7.89 & 6.18 & 8.07 & 6.35 \\
\hline StartX 300 & 18.33 & 18.60 & $* * *$ & 27.94 & 8.72 & 27.08 & 10.13 & * & 20.54 & 16.13 & 20.75 & 16.45 & & 20.67 & 16.00 & 19.73 & 17.48 \\
\hline Slope 300 & 0.17 & 0.17 & $*$ & 0.2 & 0.15 & 0.2 & 0.13 & & 0.18 & 0.17 & 0.17 & 0.16 & & 0.19 & 0.15 & 0.18 & 0.16 \\
\hline
\end{tabular}

${ }^{*} p<0.05 ;{ }^{*} p<0.01 ; * * * p<0.001$ (stars indicate significant differences among variety or fraction)

those found in the original wines and that they differed only by their polyphenol (including tannins) content (Table 1).

\section{Quantitative Descriptive Analysis}

The two-way ANOVA (sample and panelist) performed on the two design are significant at $5 \%$ for the panelist effects (not shown here). As reported in Table 4, sample effects are significant for the attributes acidity $(p=0.05)$, astringency $(p<0.001)$, roughness $(p<0.001)$, in-mouth drying $(p=$ $0.001)$, and drying after spitting $(p=0.001)$ for design A. In design $\mathrm{B}$, the attributes astringency $(p=0.01)$, roughness ( $p=$ $0.003)$, in-mouth drying ( $p=0.02)$, and drying after spitting $(p=0.01)$ were also significant.

The nested ANOVA (Table 5) shows an effect of grape variety on the attribute acidity $(p=0.04)$, roughness $(p=$

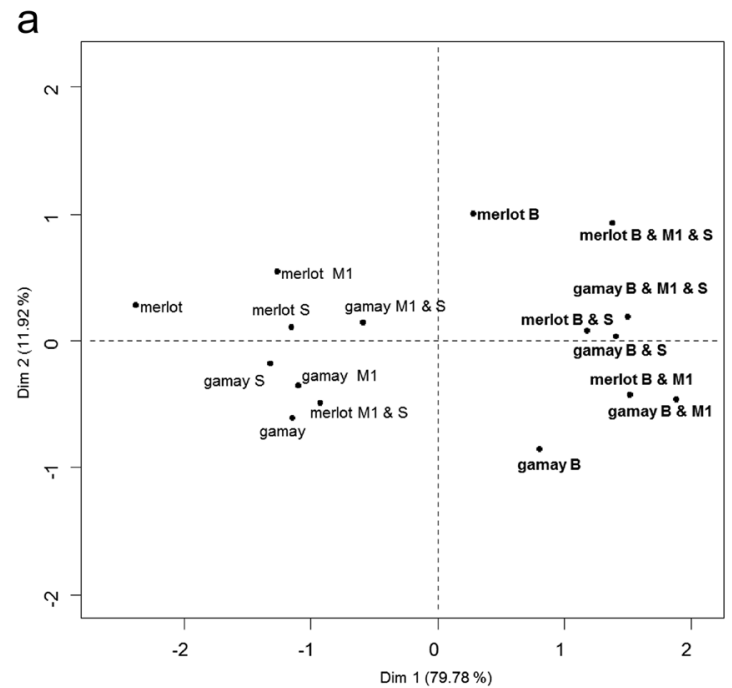

$0.03)$, and in-mouth drying $(p=0.01)$. The values of these three attributes are significantly higher for Gamay than for Merlot. This result could be explained by slightly higher total acidity of Gamay that could affect acidity and astringency perception. The values of the attributes astringency ( $p=$ $0.002)$, roughness $(p \leq 0.001)$, in-mouth drying $(p=0.002)$, and drying after spitting $(p=0.01)$ are significantly higher for samples containing fraction B (tannins of DP range $>30$ ) than for those without fraction B, and this is the case for both grape varieties. The values of the attribute in-mouth drying $(p=0.04)$ are significantly higher for samples containing fraction M1 (tannins of DP range between 15 and 30) than those without fraction M1.

PCA was performed on the samples from the two series, previously corrected for session effects (Fig. 2a, b). Only the attributes for which a significant difference has been

b

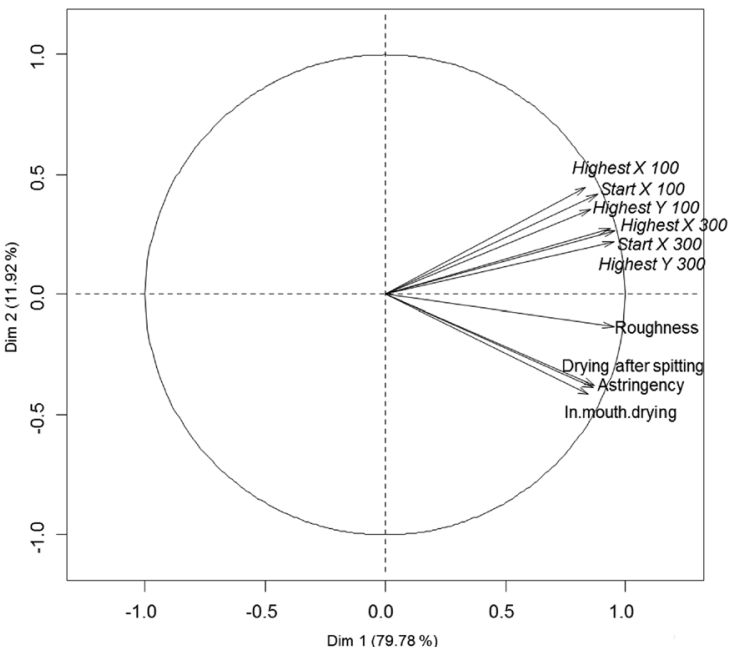

Fig. 3 a, b HMFA graphs-Representation of the sample. B-containing wine samples are indicated in bold (a). Correlation circle of the sensory attributes and nephelometric parameters (in italics) (b) 
a

Sample : Gamay M1 \& S
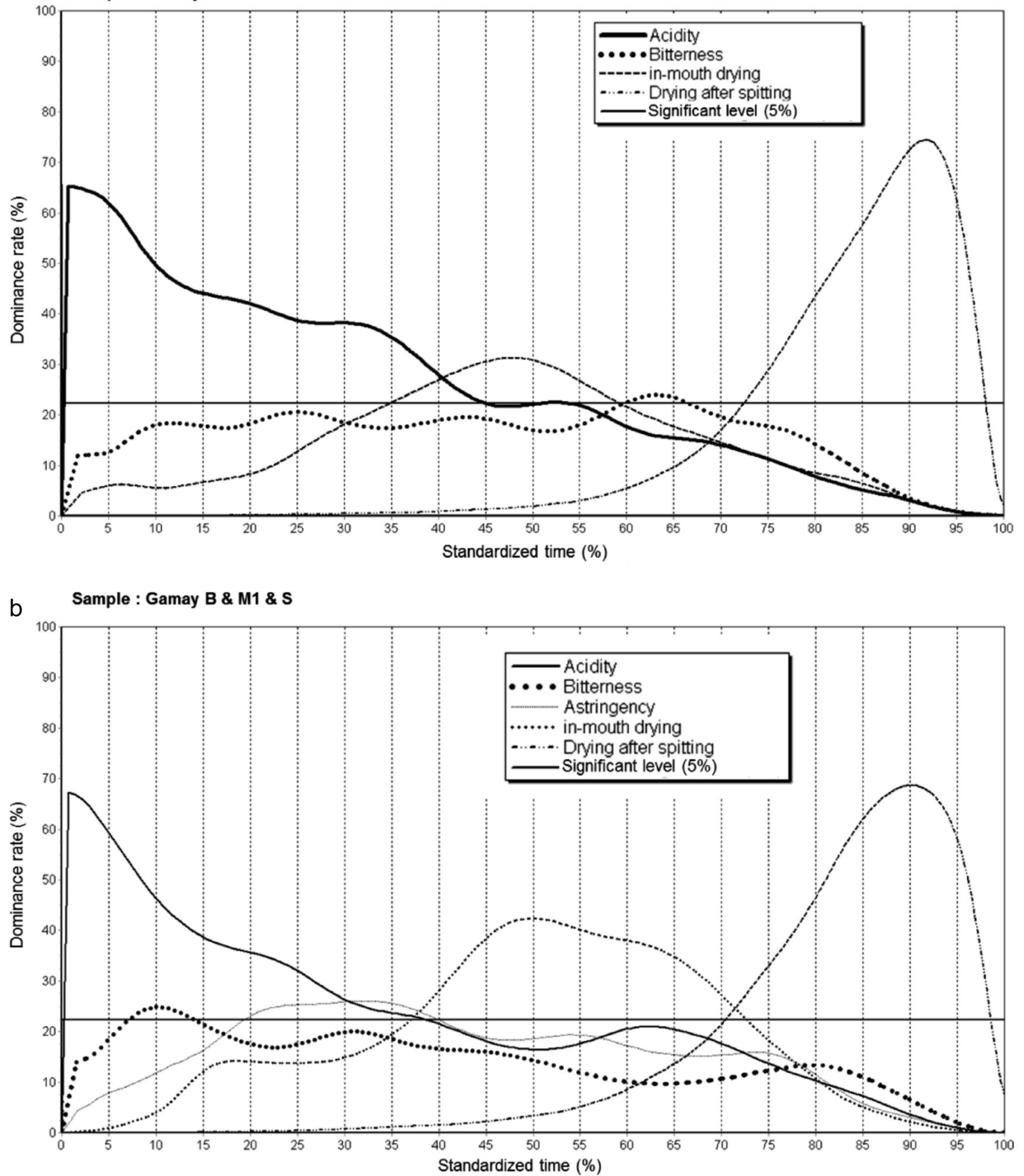

Fig. 4 a, b TDS plots of Gamay M1 \& S (a) and Gamay B \& M1 \& S (b) samples with standardized time. The straight line represents the significance level $(5 \%)$ of any attribute

determined by the ANOVA and which are common to the two series were kept. The first plane accounted for $94.48 \%$ of the total variation between products. The first principal component ( $88.98 \%$ of the total variance) was highly correlated with astringency, roughness, and in-mouth drying. All these attributes are correlated between themselves. Except for 
Merlot containing the fraction B only, all other wines containing fraction B differed from the other samples in being more astringent and having more in-mouth drying/drying after spitting characters. Their tannins were also described as being rougher.

The ultrafiltration technique selected here offers several important advantages, particularly with respect to sensory analysis. Firstly, it is a purely physical technique and no chemicals (e.g., organic solvent, buffer components) have to be used. Secondly, since ultrafiltration can preserve even the delicate structure and function of enzymatic proteins and nucleic acids, it may be safely assumed that tannin molecules will not experience any alteration during the fractionation process, even more so because this process is carried out in the absence of oxygen. Thirdly, the concentrated wine fractions B, $\mathrm{M} 1$, and $\mathrm{S}$ remain dissolved in their native wine matrix and are expected to remain in the same environment after being diluted with the polyphenol-deprived wine matrix prepared by charcoal treatment. This ensures that panelists would assess only the perceptions due to the added fraction(s). Lastly, ultrafiltration is more easily amenable to the preparative scale than chromatographic methods, allowing relatively large volumes of wine fractions to be prepared for the sensory sessions. Our results point out an important role played by the tannins of the $\mathrm{B}$ fraction obtained by ultrafiltration. In spite of a possible impact of polysaccharides concerning the $\mathrm{B}$ fraction (not addressed here), these tannins (DP range $>30$ subunits) were perceived as more astringent and drying in the mouth and drying after spitting. The two other fractions do not allow us to discriminate the sample. We also observed an important correlation between sensory attributes.

\section{Nephelometric Analysis}

The nested ANOVA (same model as for sensory data) shows an effect of the B fraction $(p<0.05)$ for all parameters except for the slope $100 \mu \mathrm{l}$ parameter (Table 6). Values of these nephelometric parameters are significantly higher for samples containing the B fraction, whereas the other fractions (M1 and S) have less impact on these parameters. When present, M1 fraction increases the StartX $300 \mu$ l parameter value $(p=0.05)$. $\mathrm{S}$ fraction increases the HighestY parameters for the two volumes $100 \mu \mathrm{l}(p=0.03)$ and $300 \mu \mathrm{l}(p=0.02)$ and StartX $100 \mu \mathrm{l}$ parameter $(p=0.03)$.

Four different parameters and two different volumes were extracted from the nephelometric curves. The impact of the B fraction was clearly underscored. Indeed, all parameters increased when the B fraction was present. However, the other fractions had less impact on nephelometric parameters. Our results show that nephelometric analysis is a good instrument to show the presence of highly polymerized tannins.

\section{Relationship Between Sensory and Nephelometric Data}

The relationship between sensory and nephelometric data was investigated using HMFA (Fig. 3a, b). Since the two nephelometric slope parameters $(100 \mu \mathrm{l}$ and $300 \mu \mathrm{l})$ were less (or not) significant, they were discarded. The axis 1 of the HMFA represented $79.78 \%$ of the total variation. On this axis, the fraction B-containing samples (in bold) are opposed to the other samples without B fraction (Fig. 3a). This opposition accounts for most of the variability between samples. The Bcontaining samples are positively correlated with all sensory attributes and nephelometric parameters (Fig 3b). The multidimensional correlation between QDA data and nephelometric data is significantly positive $(\mathrm{RV}=0.58, p=0.001)$. The sensory map of the 16 wine samples is thus highly correlated with the nephelometric parameter map.

As expected, QDA and nephelometric analysis were highly correlated. If the first dimension (79.78 \% of variability) can be explained by the presence or absence of $\mathrm{B}$ fraction, the second dimension separated sensory and nephelometric parameters but cannot be explained by the presence of a particular fraction. Another analysis was carried out using partial least squares (PLS) which confirmed the results from HMFA (data not shown).
Fig. 5 TDS differences between Merlot-B on the upper part and Merlot-M1 on the lower part of the chart with standardized time

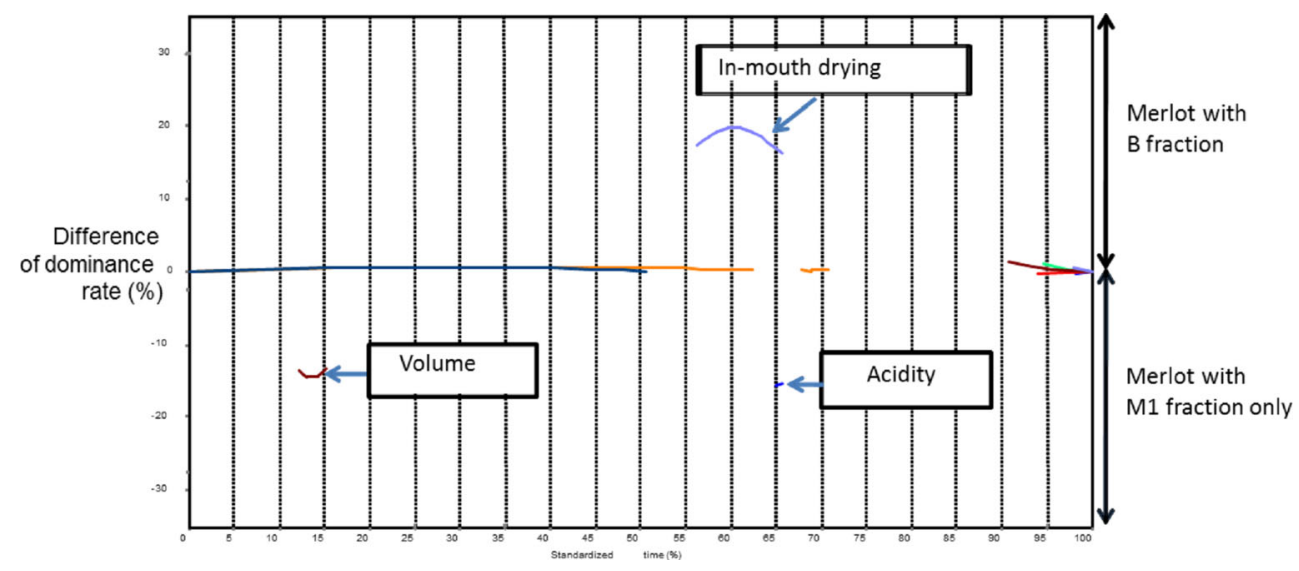




\section{Temporal Sensory Changes Measured Using TDS}

Additional information about evolution and dominance of sensations was provided by TDS analysis after curve standardization. The TDS curve started when the first attribute was selected and stopped when the attribute saliva returns was chosen. For instance, the standardized TDS curves of two different samples and for significant attributes only are shown in Fig. 4a, b. In the sample Gamay M1 \& S (Fig. 4a), the first dominant perception is acidity, followed by in-mouth drying and some bitterness before spitting. The Gamay B, \& M1 \& S sample (Fig. 4b) was characterized by an acidity perception, followed by a short astringency and finally a long in-mouth drying dominance. Moreover, the astringency and in-mouth drying perceptions were more persistent in the Gamay B, \& M1 \& S sample (15\% longer for in-mouth drying) than in the Gamay without B fraction (Fig. 4b). Again, this emphasizes the key role of fraction $\mathrm{B}$.

New features were unveiled by constructing TDS difference curves between two samples (Fig. 5). For instance, the wine sample with Merlot B fraction was significantly higher than Merlot M1 for the in-mouth drying attribute at the end of the tasting. For Merlot M1, results show significant volume and acidity even though these effects are short in time.

TDS was already used to describe the effect of dealcoholization of red wine (Meillon et al. 2009); to our knowledge, it has never been used to describe the effect of the size of tannins on the sensory evolution. Our results show that fraction B (the biggest tannins) increased the persistence of astringency and the sensation of in-mouth drying. Astringency appeared quickly when B fraction was present and the drying after spitting appeared to be longer for the samples with B fraction. The TDS confirmed the in-mouth evolution, already identified by other authors (Lesschaeve and Noble 2005; Ishikawa and Noble 1995; Robichaud and Noble 1990) with the time-intensity method, but offers an easier methodology.

\section{Conclusion}

In this study, we analyzed the impact of tannin size by sensory and nephelometric methods. We used ultrafiltration to obtain four fractions which differed by the DP range. This method allowed the physical structure of tannins and their chemical purity to be fully preserved. We analyzed three different tannin fractions (isolated from two different grape varieties) which were added to the polyphenol-depleted wine matrix. Concerning the QDA, the largest fraction (DP range $>30$ subunits) increased the perception of astringency, in-mouth drying, drying after spitting, and roughness. The dominance of astringency, in-mouth drying and drying after spitting perceptions were longer when these largest tannins were present.
Nephelometric curves were summarized by four parameters, which were all correlated with the presence of the largest tannins. Further studies are required to better describe the role of the other fractions and their impact on the nephelometric curves. Finally, QDA and nephelometric parameters were significantly correlated.

Acknowledgments The authors would like to thank all panelists for their participation, Eve Danthe for the preparation work done at the beginning of each panel session, Patrik Schonenberger for his help in writing the English version of this article, Laure Steiner Convers for her advice on the manuscript, and the Schenk winery for providing the wines used in this study.

\section{Compliance with Ethics Requirements}

Conflict of Interest The authors declare that they have no conflict of interest. study.

All persons gave their informed consent prior to their inclusion in the The manuscript does not contain clinical studies or patient data.

\section{References}

Bate-Smith EC (1954) Astringency in foods. Food 23:419-429

Carvalho E, Póvoas MJ, Mateus N, de Freitas V (2006) Application of flow nephelometry to the analysis of the influence of carbohydrates on protein-tannin interactions. J Sci Food Agric 86(6):891-896. doi:10.1002/jsfa. 2430

Chapon L (1993) Nephelometry as a method for studying the relations between polyphenols and proteins. J Inst Brew 99(1):49-56. doi:10. 1002/j.2050-0416.1993.tb01146.x

Colonna AE, Adams DO, Noble AC (2004) Comparison of procedures for reducing astringency carry-over effects in evaluation of red wines. Aust J Grape Wine Res 10(1):26-31. doi:10.1111/j.17550238.2004.tb00005.x

Condelli N, Dinnella C, Cerone A, Monteleone E, Bertuccioli M (2006) Prediction of perceived astringency induced by phenolic compounds II: criteria for panel selection and preliminary application on wine samples. Food Qual Prefer 17(1-2):96-107. doi:10.1016/j.foodqual. 2005.04.009

Dinnella C, Recchia A, Tuorila H, Monteleone E (2011) Individual astringency responsiveness affects the acceptance of phenol-rich foods. Appetite 56(3):633-642. doi:10.1016/j.appet.2011.02.017

Freitas VD, Mateus N (2002) Nephelometric study of salivary proteintannin aggregates. J Sci Food Agric 82(1):113-119. doi:10.1002/ jsfa. 1016

Gawel R, Oberholster A, Francis IL (2000) A 'mouth-feel wheel': terminology for communicating the mouth-feel characteristics of red wine. Aust J Grape Wine Res 6(3):203-207. doi:10.1111/j.17550238.2000.tb00180.x

Gawel R, Iland PG, Francis IL (2001) Characterizing the astringency of red wine: a case study. Food Qual Prefer 12(1):83-94. doi:10.1016/ S0950-3293(00)00033-1

Granès D, Pic-Blateyron L, Negrel J, Bonnefond C (2009) L'analyse sensorielle descriptive quantifiée (ASDQ), une méthode pour un langage commun. Rev Oen 238:16-21

Green BG (1993) Oral astringency: a tactile component of flavor. Acta Psychol 84(1):119-125. doi:10.1016/0001-6918(93)90078-6 
Guinard JX, Pangborn RM, Lewis MJ (1986) Preliminary studies on acidity-astringency interactions in model solutions and wines. $\mathrm{J}$ Sci Food Agric 37(8):811-817. doi:10.1002/jsfa.2740370815

Hagerman AE, Butler LG (1981) The specificity of proanthocyanidinprotein interactions. J Biol Chem 256(9):4494-4497

Holt HE, Francis IL, Field J, Herderich MJ, Iland PG (2008) Relationships between wine phenolic composition and wine sensory properties for Cabernet Sauvignon (Vitis vinifera L.). Aust J Grape Wine Res 14(3):162-176. doi:10.1111/j.1755-0238.2008.00020.x

Ishikawa T, Noble AC (1995) Temporal perception of astringency and sweetness in red wine. Food Qual Prefer 6(1):27-33. doi:10.1016/ 0950-3293(94)P4209-O

Josse J, Pagès J, Husson F (2008) Testing the significance of the RV coefficient. Comput Stat Data Anal 53(1):82-91. doi:10.1016/j. csda.2008.06.012

Kauffman DL, Keller PJ (1979) The basic proline-rich proteins in human parotid saliva from a single subject. Arch Oral Biol 24(4):249-256. doi:10.1016/0003-9969(79)90085-2

Labbe D, Schlich P, Pineau N, Gilbert F, Martin N (2009) Temporal dominance of sensations and sensory profiling: a comparative study. Food Qual Prefer 20(3):216-221. doi:10.1016/j.foodqual. 2008.10.001

Le Dien S, Pagès J (2003) Hierarchical multiple factor analysis: application to the comparison of sensory profiles. Food Qual Prefer 14(56):397-403. doi:10.1016/S0950-3293(03)00027-2

Lea AH (1992) Flavor, color, and stability in fruit products: the effect of polyphenols. In: Hemingway R, Laks P (eds) Plant Polyphenols, vol 59. Basic Life Sciences. Springer US, pp 827-847. doi:10.1007/ 978-1-4615-3476-1 49

Lesschaeve I, Noble AC (2005) Polyphenols: factors influencing their sensory properties and their effects on food and beverage preferences. Am J Clin Nutr 81(1):330S-335S

Mateus N, Pinto R, Ruão P, de Freitas V (2004) Influence of the addition of grape seed procyanidins to Port wines in the resulting reactivity with human salivary proteins. Food Chem 84(2):195-200. doi:10. 1016/S0308-8146(03)00201-2

McManus JP, Davis KG, Lilley TH, Haslam E (1981) The association of proteins with polyphenols. J Chem Soc Chem Commun (7):309b311. doi:10.1039/C3981000309B

Meillon S, Urbano C, Schlich P (2009) Contribution of the temporal dominance of sensations (TDS) method to the sensory description of subtle differences in partially dealcoholized red wines. Food Qual Prefer 20(7):490-499. doi:10.1016/j.foodqual.2009.04.006

Monteleone E, Condelli N, Dinnella C, Bertuccioli M (2004) Prediction of perceived astringency induced by phenolic compounds. Food Qual Prefer 15(7-8):761-769. doi:10.1016/j.foodqual.2004.06.002

Pineau N, Schlich P, Cordelle S, Mathonnière C, Issanchou S, Imbert A, Rogeaux M, Etiévant P, Köster E (2009) Temporal dominance of sensations: construction of the TDS curves and comparison with time-intensity. Food Qual Prefer 20(6):450-455. doi:10.1016/j. foodqual.2009.04.005

Porter LJ, Hrstich LN, Chan BG (1985) The conversion of procyanidins and prodelphinidins to cyanidin and delphinidin. Phytochemistry 25(1):223-230. doi:10.1016/S0031-9422(00)94533-3

Quintana M, Palicki O, Lucchi G, Ducoroy P, Chambon C, Salles C, Morzel M (2009) Short-term modification of human salivary proteome induced by two bitter tastants, urea and quinine. Chem Percept 2(3):133-142. doi:10.1007/s12078-009-9048-2

Ribéreau-Gayon P, Glories Y, Maujean A, Dubourdieu D (1998) Les composés phénoliques. In: Dunod (ed) Traité d'œnologie, tome 2, chimie du vin - stabilisation et traitements, 2nd edn. Paris, pp 163 237

Robichaud JL, Noble AC (1990) Astringency and bitterness of selected phenolics in wine. J Sci Food Agric 53(3):343-353. doi:10.1002/ jsfa. 2740530307

Saucier C, Bourgeois G, Vitry C, Roux D, Glories Y (1997) Characterization of $(+)$-catechin-acetaldehyde polymers: a model for colloidal state of wine polyphenols. J Agric Food Chem 45(4): 1045-1049. doi:10.1021/jf960597v

Törnwall O, Dinnella C, Keskitalo-Vuokko K, Silventoinen K, Perola M, Monteleone E, Kaprio J, Tuorila H (2011) Astringency perception and heritability among young Finnish twins. Chem Percept 4(4): 134-144. doi:10.1007/s12078-011-9098-0

Vidal S, Courcoux P, Francis L, Kwiatkowski M, Gawel R, Williams P, Waters E, Cheynier V (2004) Use of an experimental design approach for evaluation of key wine components on mouth-feel perception. Food Qual Prefer 15(3):209-217. doi:10.1016/S09503293(03)00059-4

Wood SN (2006) Generalized additive models: an introduction with R Broken sound parkway nw, Boca Raton

Wu A, Csako G, Herp A (1994) Structure, biosynthesis, and function of salivary mucins. Mol Cell Biochem 137(1):39-55. doi:10.1007/ BF00926038 